6 Burgess EH. Ear wax - and the right way to use an ear syringe. Nursing Times $1977 \cdot 73 \cdot 156+-5$

7 Hinchcliffe R. Prevalence of the commoner ear, nose and throat conditions in the adult rural population of Great Britain. British fournal of Preventive and Social Medicine 1961:15:128-40.

8 Warwick-Brown NP. Wax impaction in the ear. Practitioner 1986;230:301

9 Anonymous. Wax in the ear [Editorial]. Br.Med f 1972;iv:623-4.

10 Mevers AD. Practical ENT: managing cerumen impaction. Postgrad Med 1977;62:207-9.

11 Sim DW. Wax plugs and cotton buds. F Larvngol Otol 1988; 102:575-6.

12 Horowitz JI. Solvents for ear wax. Br.Med f 1968;iv:583.
13 Fraser JG. The efficacy of wax solvents: In vitro studies and a clinical trial. f Laryngol Otol 1970;84:1055-64.

14 Anonymous. Ear wax solvents compared. Drug Ther Bull 1971;9:15-6

15 Chaput de Saintonge DM, Johnstone CI. A clinical comparison of triethanot amine polypeptide oleatecondensate ear drops with olive oil for the removal of impacted wax. Brf Clin Practice 1973;27:454-5.

16 Fahmey S, Whitefield M. Multicentre clinical trial of Exterol as a cerumenolytic. Br f Clin Pract 1982;36: 197-204

17 Seiler ER. Ear syringing. Br Med f 1980;280:1273.
Royal Hospital for Sick Children, Glasgow G3 8SJ Fiona A Logan, MRCPSYCH, research registrar

A Maclean, MAPPSCI, senior clinical psychologist, department of child and family psychiatry

B Gibson, MRCPATH, consultant haematologist

Department of Haematology, The Hospitals for Sick Children, London I M Hann, MD, consultant haematologist

University of Glasgow, Glasgow

C A Howie, BSC, statistician, department of materia medica W L Parry-Jones, FRCPSYCH, professor of child and adolescent psychiatry

Correspondence to: Dr F A Logan, Westcotes House, Westcotes Drive, Leicester LE3 0QU.

BrMed f 1990;301:1253-6

\title{
Psychological disturbance in children with haemophilia
}

\author{
Fiona A Logan, A Maclean, C A Howie, B Gibson, I M Hann, W L Parry-Jones
}

\section{Abstract}

Objective-To assess the need for formal psychotherapeutic intervention in children attending a children's haemophilia clinic after some of them had been diagnosed as positive for HIV.

Design-Comparison of haemophiliac children with matched control groups of diabetic and healthy children.

Setting-The West of Scotland Children's

Haemophilia Centre, Glasgow.

Patients -43 Children aged 3 to 16 years with mild, moderate, and severe clotting disorders were matched with control groups of $\mathbf{4 6}$ diabetic children and 42 physically healthy children.

Interventions - Parents of children aged 3-5 years were interviewed with the behaviour screening questionnaire. Children aged 6 to 16 were assessed by parental and teacher report using standardised questionnaires and self report using a computerised depression inventory. All were scored numerically according to the presence of symptoms of emotional and behavioural problems.

Main outcome measures-The groups were compared for mean scores on each rating device and for number of children achieving scores within the pathological range.

Results - In the 6-16 age group five haemophiliac children, five diabetic children, and three healthy children scored in the pathological range on the parent questionnaire, as did two, three, and five respectively on the teacher questionnaire and four, four, and eight on the depression inventory. There was no significant difference across the three groups. Analysis of mean scores similarly showed no significant difference across groups. In contrast, the single measure used for younger children showed an increase in behavioural difficulties among the diabetic children.

Conclusion-Haemophiliac children attending the West of Scotland Centre were no more disturbed than their diabetic or healthy peers despite the identification of HIV infection within the clinic and the widespread adverse publicity associated with AIDS and HIV infection.

\section{Introduction}

The care of chronically ill children has progressively supplanted the care and cure of acutely ill children in Western paediatric practice. ${ }^{12}$ Whereas physically healthy children have rates of psychiatric disturbance varying from $6.6 \%$ in the Isle of $\mathrm{Wight}^{3}$ to $17 \%$ in Blackburn ${ }^{+}$chronically ill children may have higher rates, estimated variously at $10.4 \%$ in the Isle of Wight (excluding neurological disorders) to $30 \%$ in Rochester, New York. ${ }^{5}$ Reports on the psychosocial effects of haemophilia are extensive and conflicting. Early descriptive papers drew attention to severe adjustment problems and to such practical difficulties as missed schooling, unemployment, and poor social functioning. ${ }^{6.9}$ Some more recent papers have echoed these findings, ${ }^{1011}$ but others have reported little or no difference between children with haemophilia and the general population on measures of school attendance, social adjustment, and personality. ${ }^{1213}$ We devised this study to determine the prevalence of psychiatric disorder in children with haemophilia attending the West of Scotland Children's Haemophilia Centre.

\section{Method}

The study population comprised children registered with the West of Scotland Children's Haemophilia Centre. When more than one child per family was affected the elder child was taken as the index child for study. Of 61 families registered as having one or more children with haemophilia or other bleeding disorders, $53(86 \%)$ agreed to participate. Of the index children, 30 were diagnosed as having classic haemophilia A, seven had haemophilia $\mathrm{B}, 10$ had von Willebrand's disease, and six had various rarer bleeding disorders.

\section{CONTROLS}

The diabetic clinic, based in the same children's hospital as the haemophilia centre, provided a control group of 51 diabetic children matched to the haemophiliac children by age, sex, social class, and birth order. The use of a diabetic group controlled for the non-specific effects of chronic illness in childhood, thus allowing assumptions to be made about effects specific to haemophilia. A second control group of 49 healthy children was obtained from seven general practices throughout the west of Scotland, reflecting the geographic scatter (urban, coastal, and rural) of the haemophiliac group and matched for age, sex, social class, and birth order. This second control group allowed comparison with healthy peers growing up in similar surroundings.

Matching for both diabetic and healthy control groups was initially achieved by identifying from clinic and practice age-sex registers children who were of the same sex with a birth date within six months of each child with haemophilia. Practice and clinic notes were then used to obtain information about birth order, family size, and father's occupation. Children with a current or previous referral to a psychiatric or psychology clinic were excluded. In the healthy group the matched child and any siblings were also required to be free of any chronic illness and any condition that required attendance at a hospital outpatient clinic in the preceding two years. The first child identified as of correct birth order, family size, and social class who met all these criteria was selected.

\section{ASSESSMENT}

The assessment protocol applied to the families was 
the same in each group. The psychiatric state of children aged 3-5 years was assessed by Richman's behaviour screening questionnaire. For children aged 6-16 the parents were asked to complete Rutter's parent questionnaire and to give permission for teachers to complete Rutter's teacher questionnaire. ${ }^{3}$ Those children who had completed two or more years of primary education were asked to complete Kovac's children's depression inventory, which was presented on a microcomputer, so that the child could read the questions directly and key in responses. All these questionnaires are designed for population screening for evidence of psychiatric disturbance and have been well validated and described. The recommended cut off points in the Rutter and Richman questionnaires were used to determine the score above which someone is likely to be suffering from a psychiatric disorder ("caseness"). These were scores of 13 for the parent questionnaire, nine for the teacher questionnaire, and 10 for the behaviour screening questionnaire. A score of nine or more on the children's depression inventory was taken as representing an undesirable level of anxious or depressive responses. ${ }^{151718}$

\section{ANALYSIS}

Demographic details were analysed for differences by cross tabulation followed by formal analysis with the $\chi^{2}$ test, which assesses the independence of each group and variable. The relation between "caseness," demographic factors, and severity of haemophilia was analysed in the same way. In addition, the actual scores on the parent and teacher and behaviour screening questionnaires were analysed by one way analysis of variance after appropriate transformation to normalise the distribution. The power of the study ${ }^{19}$ was calculated for the parent and teacher questionnaires and for the behaviour screening questionnaire. A difference of four in mean scores was selected as likely to have clinical significance for all three measures. On this basis the power of the study correctly to find this difference at $p<0.05$ was $85 \%$ for the parent questionnaire, $99 \%$ for the teacher questionnaire, and $98 \%$ for the behaviour screening questionnaire. The results are presented separately for the two age groups.

\section{Results}

\section{CHILDREN AGED 6-16 YEARS}

The haemophiliac and diabetic groups each contained 32 children in this age range, and there were 34 in the healthy group. Each group contained eight girls. In the healthy group, two children had had their sixth birthdays and moved into the older age group before being assessed, thus accounting for the apparent excess in this group. The mean ages of the children in months were 123 (SD 34) in the haemophiliac group, 125 (28) in the diabetic group, and 121 (30) in the healthy group. The groups were well matched for social class, birth order, family size, and paternal employment.

Parent questionnaires were returned for 29 haemophiliac, 30 diabetic, and 33 healthy children. The groups had similar mean scores and proportions of children whose scores fell into the "case" category (table I).

Teacher questionnaires were returned for 28 haemophiliac, 27 diabetic, and 30 healthy children. Although

TABLE I-Results of parent questionnaire for children aged 6-16 years

\begin{tabular}{lcc}
\hline & Case/non-case & Mean (SD) score \\
\hline Haemophiliac children $(\mathrm{n}=29)$ & $5 / 24$ & $7 \cdot 34(4 \cdot 97)$ \\
Diabetic children $(\mathrm{n}=30)$ & $5 / 25$ & $7 \cdot 43(5 \cdot 10)$ \\
Healthy children $(\mathrm{n}=33)$ & $3 / 30$ & $7 \cdot 24(4 \cdot 44)$ \\
\hline & & \\
\hline$\chi^{2}$ test, $\mathrm{p}=0 \cdot 59 ;$ one way analysis of variance, $\mathrm{p}=0 \cdot 99 ; 95 \%$ confidence \\
intervals for difference in mean, $-2 \cdot 2$ to $2 \cdot 3$ for haemtophiliac compared \\
with healthy children and $-2 \cdot 1$ to $2 \cdot 4$ for diabetic compared with healthy.
\end{tabular}

TABLE II-Results of teacher questionnaire for children aged 6-16 year

\begin{tabular}{lcc}
\hline & Case/non-case & Mean $($ SD $)$ score \\
\hline Haemophiliac children $(n=28)$ & $2 / 26$ & $2 \cdot 11(3 \cdot 10)$ \\
Diabetic children $(n=27)$ & $3 / 24$ & $4 \cdot 56(6 \cdot 25)$ \\
Healthy children $(n=30)$ & $5 / 25$ & $3 \cdot 03(4 \cdot 34)$
\end{tabular}

$\gamma^{2}$ test $=0.41$; one way analysis of variance, $\mathrm{p}=0.13 ; 95 \%$ confidence $\chi^{2}$ cest $-0.41 ;$ one way analysis of variance, $\mathrm{p}=0-13 ; 95 \%$ confidence with healhy childen and -1.4 in 3.9 for diabetic compariac compared children.

TABLE III - Results of children's depression inventory for children aged 6-16 years

\begin{tabular}{|c|c|c|}
\hline & Case/non-case & Mean (SD) score \\
\hline Haemophiliac children $(\mathrm{n}=23)$ & $4 / 19$ & $4.57(3.53)$ \\
\hline Diabetic children $(n=27)$ & $4 / 23$ & $4 \cdot 48(4 \cdot 40)$ \\
\hline Healthy children $(n=26)$ & $8 / 18$ & $6.08(4 \cdot 77)$ \\
\hline
\end{tabular}

$\chi^{2}$ test, $p=0 \cdot 3 ; 95 \%$ confidence intervals for difference in mean, -3.5 to $0 \cdot 1$ for haemophiliac compared with healthy children and -3.4 to 0.8 for diabetic compared with healthy children.

there was slightly more variation in the mean scores for each group than with the parent questionnaire, this did not approach significance (table II), and the proportion of children categorised as "cases" did not differ significantly across the groups.

Children's depression inventory - The three groups did not differ significantly in mean scores or number of children scoring above the selected cut off point of 9 (table III).

"Caseness"-Only two children, both diabetic, were identified as "cases" on all three measures. Two more children, one diabetic and one healthy, were identified as "cases" on both parent and teacher questionnaires. One healthy child was identified as a "case" on both the depression inventory and the teacher questionnaire. Eleven haemophiliac, four diabetic, and 12 healthy children were identified on a single measure. "Caseness" on any of the measures was not related to age, sex, birth order, family size, family structure, social class, paternal or maternal employment, or to HIV state.

Children positive for HIV-All the families whose children had been infected by HIV in the course of treatment for haemophilia agreed to participate in the study. They were seven families with a total of 10 haemophiliac sons, all of whom were HIV positive. One attended an adult clinic and was too old for the measures used in this study. In accordance with the study design, seven of these children were assessed as part of the index group of children with haemophilia and two as part of the sibling group for which the same measures were used. The information from all nine HIV positive children is presented. All three measures were obtained for seven of the HIV positive children, but only the results of the teacher questionnaire were obtained for the remaining two children, whose parents did not want the children interviewed and did not complete the parent questionnaire. At assessment one child was 9 years old, three were 11 , and five were 12. Four children, two aged 11 and two aged 12, had been told by their parents that they were HIV positive. Of these, one child scored as a "case" on the parent questionnaire, two scored in the normal range in all three measures, and the fourth was rated only on the teacher questionnaire with a normal score. The remaining five were believed to be unaware of their HIV state. Of these five, four had normal scores on all three measures and one (on whom no other measure was obtained) scored as a "case" on the teacher questionnaire. The HIV positive group thus did not differ from the HIV negative haemophiliac group or the control groups in measurable psychiatric morbidity. Knowledge of HIV state was not related to morbidity in this small sample. 
Severity - Ten haemophiliac children were classified as severely affected (31\%), seven as moderately affected $(22 \%)$, and 15 as mildly affected $(47 \%)$ by conventional laboratory criteria. Severity was not related to patterns of parental employment, family breakdown, or to "caseness" on any of the three measures. In three children clinical severity was rated severe, whereas the laboratory rating was moderate, but this was not correlated with "caseness."

\section{CHILDREN AGED 3-5 YEARS}

Eleven index haemophiliac children (nine boys and two girls) were aged 3-5 years (mean age 59 months). There were 14 diabetic children ( 11 boys and three girls, mean age 51 months) and eight healthy children (seven boys and one girl, mean age 45 months). The uneven distribution of children in this age group reflects the difficulties of precise age matching of young children with a congenital condition to those with an acquired condition. The groups were well matched demographically.

Behaviour screening questionnaire results showed that there was an excess of cases in the diabetic group (table IV). "Caseness" was unrelated to age, sex, rank, sibship, social class, parental employment, or family structure.

TABLE IV-Results of behaviour screening questionnaire for children aged 3-5 years

\begin{tabular}{lcc}
\hline & Case/non-case & Mean (SD) score \\
\hline Haemophiliac children $(n=11)$ & $1 / 10$ & $5 \cdot 55(3 \cdot 0)$ \\
Diabetic children $(n=14)$ & $8 / 6$ & $9 \cdot 21(5 \cdot 0)$ \\
Healthy children $(n=8)$ & $2 / 6$ & $7 \cdot 25(3 \cdot 40)$
\end{tabular}

$\gamma^{2}$ test, $\mathrm{p}=0.03$; one way analysis of variance, $\mathrm{p}=0.09 ; 95 \%$ confidence intervals for difference in mean, -4.8 to 1.4 for haemophiliac compared with healthy children and -1.7 to 5.7 for diabetic compared with healthy children.

\section{Discussion}

The study was begun when media coverage of HIV infection was at its most intense. Families of both infected and non-infected haemophiliac children had to deal with grave fears for their children's continued wellbeing and growing concern about the safety of the treatment on which their children's lives depended. Public panic and outrage did not distinguish children with haemophilia from other groups at high risk of HIV infection. Where previously a child's haemophilia had led to concern and protectiveness it became for a time a terrifying threat. Parents and staff of the haemophilia centre tried to protect the children from the worst publicity and the impact of measures taken to prevent any possible cross infection. Children who were accustomed to ordinarily dressed staff and admission to an open ward suddenly found themselves tended by heavily gowned and masked staff using ultrasterile techniques for routine procedures, and they were barred from the open ward and the usual contact with other child patients. Thus the research group expected that this study would find a high level of psychopathology in haemophiliac children and a substantial need for psychotherapeutic intervention.

The finding that haemophiliac children in the west of Scotland aged 3-16 years do not differ from matched healthy children on three screening instruments for psychiatric disturbance and a further self reported measure of anxiety and depression is therefore of considerable interest and clinical significance, particularly in view of previous findings of increased rates of disturbance in chronically ill children, including those with haemophilia. It is particularly striking that the adverse publicity and increased level of awareness of the dangers of HIV infection for the haemophiliac population were not reflected in the findings for the children.

There are several possible explanations for the apparent "normality" of the haemophiliac group. Firstly, the samples may be too small to show a true difference in the incidence of psychiatric disturbance in the population of children with haemophilia. The statistical power calculations, however, suggest that this is unlikely to be the case. Secondly, the findings may be a consequence of bias in the recruiting of the control groups, with overrepresentation of "cases" giving a false impression of no increase in the haemophiliac group. In fact the opposite sort of bias was anticipated by excluding from the study both diabetic and healthy controls known to be attending child psychiatry services. Recruitment of healthy control families varied from one third to all families contacted in a given practice, raising the possibility of self selection bias in the less responsive practices. Nevertheless two practices representing $36 \%$ of the healthy controls had a $100 \%$ take up, which should have diminished this source of bias. It seemed likely that difference in response was due partly to poor timing of approach in the weeks before Christmas and partly to the greater mobility of inner city practice populations with less well established links between families and practices.

Alternatively, it may be that the findings reflect the very substantial psychosocial support and therapeutic input provided by the staff of the haemophilia centre from which the subjects were drawn. A permanent "haemophilia" doctor and nursing sister provide a five day walk in clinic service as well as regular outpatient clinic reviews. Further input comes from a consultant haematologist and a social worker. Physiotherapy and dental services are regularly provided. Additionally, it may be that improved quality of life resulting from better medical treatment has reduced the burden of these conditions and the likelihood of secondary disturbance. Provision for the support and care of children and families attending the diabetic clinic was of a comparable standard, and teaching of the children emphasised a positive approach towards themselves and their illness. This may effect a degree of cognitive restructuring with diminution of negative and self critical attitudes and may explain the lower children's depression inventory scores of the ill groups as many of the items reflect self esteem.

The finding of no greater level of psychiatric disturbance in the small group of HIV positive children was surprising in view of the combined stresses of life threatening infection resulting from the very treatment on which they depend and the widespread adverse publicity surrounding the AIDS issue. It remains to be seen whether the HIV positive children will become more disturbed when their infection becomes clinically apparent. Both of the HIV positive children who scored as "cases" had other psychosocial risk factors in their families which antedated the HIV infection.

The results for the children aged 3-5 years, in whom the behaviour screening questionnaire was the only index of disorder, suggest more disorder in younger diabetic children, but this requires further investigation. One possible explanation is that in younger diabetic children the higher scores reflected the more recent onset of the disease rather than an age related increase in vulnerability. Also, the sample of children with diabetes was not random and may not be representative. It would be inappropriate to extrapolate from these findings to diabetic children as a whole.

\section{Conclusions}

This study seems to contradict the widely held clinical belief that chronic illness in childhood con- 
tinues to carry a greater risk of psychiatric disturbance. It cannot be assumed from present evidence that the findings of this study are a consequence of current practice in haemophilia care, although it may well be so. Only after further investigation will it be possible to determine clinical policies and deploy resources on the basis of accurate information about children's needs.

This study was supported by the Yorkhill Leukaemia and Cancer Research Fund. We thank Dr A Pettigrew and Sister C Murphy of the haemophilia clinic and Dr J M Richardson and Sister M Maclean of the diabetic clinic. General practitioners in Glasgow, Kirkintilloch, Bearsden, Alexandria, and Isle of Bute generously helped in recruiting control subjects. Professor F H Stone and Dr V Kusumaker were instrumental in setting up the project.

1 Haggerty RJ. Preface. In: Pless IB, Pinkerton P, eds. Chronic childhood disorder-promoting patterns of adjustment. London: Henry Kimpton, 1975:11.

2 Rae-Grant Q. Psychological problems in the medically ill child. Pediatr Clin North Am 1985;8:653-63.

3 Rutter M, Tizard J, Whitmore K. Education, health and behaviour. London Longman, 1970.

4 Leslie SA. Psychiatric disorder in the adolescents of a new town. $\mathrm{Br} \mathcal{J}$ Psychiatry 1974;125:113-24.

5 Pless IB, Roghman KJ. Chronic illness and its consequences: observation based on three epidemiologic surveys. I Pediatr 1971;79:351-9.

6 Mattson A, Gross S. Adaptational and defensive behaviour in young haemophiliacs and their parents. Am f Psychiatry 1966;122:1349-56.

7 Bronks IG, Blackburn EK. A socio-medical study of haemophilia and related sronks IG, Blackburn EK. A socio-medical study of haemophilia and re
states. British fournal of Preventive and Social Medicine 1968;22:68-72.

states. Britsh fournal of Preventive and Social Medicine 1968;22:68-72.
Spencer RF. Incidence of social and psychiatric problems in a group of haemophiliac patients. N C Med f 1968;29:332-5.

Boon RA, Roberts DF. The social impact of haemophilia. 7 Biosoc $S c i$ 1970;2:237-64.
.

10 Markova I, Lockyer R, Forbes CD. Haemophilia: a survey on social issues. Health Bull (Edinb) 1977;35:177-82.

11 Meijer A. Psychiatric problems of haemophilic boys and their families. Int $\mathcal{P}$ Psychiatry Med 1980;10:163-72.

12 Maclean A. The haemophiliac in school: issues of adjustment and communication [Dissertation]. Glasgow: University of Glasgow, 1985:17-27.

13 Steinhausen H-C. Chronically ill and handicapped children and adolescents: personality studies in relation to disease. F Abnorm Child Psychology 1981;9:291-7.

14 Richman N, Stevenson J, Graham PJ. Pre-school to school: a behavioural study. London: Academic Press, 1982.

15 Kovacs M. The children's depression inventory. Psychopharmacol Bull 1985;21:995-8.

16 Kovacs M, Brent D, Steinberg TF, Paulauskas S, Reid J. Children's selfreports of psychologic adjustment and coping strategies during first year of insulin-dependent diabetes mellitus. Diabetes Care 1986;9:472-9.

17 Knight D, Hensley VR, Waters B. Validation of the children's depression scale and the children's depression inventory in a prepubertal sample. $f$ Child Psychol Psychiatry 1988;29:853-63.

18 Smucker MR, Craighead WE, Craighead LW, Green BJ. Normative and reiiability data for the children's depression inventory. I Abnorm Child Psychol 1986;14:25-39.

19 Gore SM, Altman DG. Statistics in practice. London: BMA, 1989.

(Accepted 19 September 1990)

\title{
Increased energy expenditure in Parkinson's disease
}

\author{
Samuel Levi, Malcolm Cox, Myriam Lugon, \\ Malcolm Hodkinson, Andrew Tomkins
}

Department of Geriatric

Medicine, University

College and Middlesex

Hospital School of

Medicine, St Pancras

Hospital, London

NW1 2PE

Samuel Levi, MB, registrar

Myriam Lugon, MRCP, senior registrar

Malcolm Hodkinson, FRCP, professor

\section{Clinical Nutrition Unit,}

Department of Clinical

Sciences, London School

of Hygiene and Tropical

Medicine, London

WC1E 7HT

Malcolm Cox, MSC, scientist

Andrew Tomkins, FRCP,

senior lecturer

Correspondence to:

Professor A Tomkins,

Department of International

Child Health, Institute of

Child Health, Guilford

Street, London

WCIN 1EH.

Br.Med F 1990;301:1256-7
We have noted that patients with Parkinson's disease tend to be thin compared with other subjects but, apart from a recent report, this observation is not recorded in the literature. ${ }^{1}$ Weight loss is to be expected if there is a discrepancy between dietary intake and energy expenditure. In view of the considerable changes in muscular tone and involuntary movements that are characteristic of patients with Parkinson's disease we investigated energy expenditure in patients before and after treatment for their disease.

\section{Patients, methods, and results}

Fourteen patients with Parkinson's disease were studied ( 9 women and 5 men, mean age 70.4 (SE 5.8) years). Sixteen healthy elderly volunteers (il women and 5 men, mean age $76.5(9.0)$ years) were also studied. The protocol was approved by the ethical committee of the school of medicine.

Patients with Parkinson's disease weighed less than healthy subjects $(60.9(10.8) \mathrm{kg} v 66.8(12.6) \mathrm{kg})$. Patients with Parkinson's disease also had less lean body mass, calculated from skinfold measurements $(46.6(7 \cdot 6) \mathrm{kg} v 50 \cdot 2(11 \cdot 2) \mathrm{kg}),{ }^{2}$ but these differences were not statistically significant.

Resting energy expenditure was measured by indirect calorimetry using a ventilated hood technique in which a transparent acrylic hood is placed over the subject's head and shoulders and expired air is sucked from the hood continuously; the concentrations of
Energy expenditure (mean $(S D) \mathrm{kF} / \mathrm{kg}$ body weight $/ 24 \mathrm{~h}$ ) before and after drug treatment for Parkinson's disease

\begin{tabular}{lcccc}
\hline & $\begin{array}{c}\text { Patients with no } \\
\text { clinical change } \\
(\mathrm{n}=8)\end{array}$ & $\begin{array}{c}\text { Patients with } \\
\text { reduction of } \\
\text { hypertonia }(\mathrm{n}=3)\end{array}$ & $\begin{array}{c}\text { Patients with } \\
\text { increased voluntary } \\
\text { movements }(\mathrm{n}=3)\end{array}$ & Controls $(\mathrm{n}=16)$ \\
\hline $\begin{array}{l}\text { Before treatment } \\
\text { After treatment }\end{array}$ & $94 \cdot 5(14 \cdot 6)$ & $116 \cdot 2(19 \cdot 6)$ & $\left.\begin{array}{c}92 \cdot 0(14 \cdot 6) \\
115 \cdot 8(36 \cdot 8)\end{array}\right\} 81 \cdot 1(8 \cdot 4)$ \\
\hline
\end{tabular}

oxygen and carbon dioxide were measured with equipment described elsewhere. ${ }^{3}$ Values for resting energy expenditure were obtained from standard equations using the concentrations of carbon dioxide and oxygen in expired air at a time when the levels had reached steady state for at least 10 minutes. In practice, this was after 20-30 minutes of wearing the hood.

Measurements were made in the morning, the patient not having taken food or their drugs for Parkinson's disease since the previous evening, though drinks of water were allowed. Patients then took their normal dose of drug and a second measurement was made once the "new" level of neuromuscular tone and involuntary movements had become established. In practice, this was within 60 minutes of the initial measurement.

The response to the drug was variable. In eight patients there was negligible change; involuntary movements did not occur and changes in muscle tone were minimal. The remaining six patients showed striking clinical changes. Three had appreciable hypertonia during the first measurement and showed a reduction in muscle tone after swallowing their tablets. A further three were mildly hypertonic before treatment and developed striking involuntary movements shortly after swallowing their tablets. The table compares the results in these three groups with those in controls.

Overall, the resting energy expenditure in patients with Parkinson's disease was significantly $(p<0.005)$ higher than in healthy subjects whether the data were expressed as mean (SD) $\mathrm{kJ} / \mathrm{kg}$ body weight $/ 24 \mathrm{~h}(98 \cdot 6$ $(17 \cdot 1) v 81 \cdot 1(8 \cdot 4))$ or as $\mathrm{kJ} / \mathrm{kg}$ lean body mass $/ 24 \mathrm{~h}$ $(128 \cdot 3(17 \cdot 1) v 109 \cdot 5(11 \cdot 7))$. There was little change in resting energy expenditure after drug treatment in eight patients with no clinical change, but patients in whom a hypertonic state was caused by drugs showed a reduction in resting energy expenditure and those in whom involuntary movements were released by drugs showed an increase.

\section{Comment}

The importance of maintaining adequate nutritional state of the elderly, especially during illness, is increasingly recognised. ${ }^{4}$ In many elderly subjects the main reason for malnutrition is a reduction in dietary intake for a variety of biological, social, and cultural reasons. Our data suggest that some patients with Parkinson's 